University of Wollongong

Research Online

Faculty of Commerce - Papers (Archive)

Faculty of Business and Law

$1-1-2007$

\title{
Discretionary expenditure and tourism consumption: insights from a choice experiment
}

\author{
G. I. Crouch \\ La Trobe University \\ H. Oppewal \\ Monash University \\ T. Huybers \\ University of New South Wales \\ Sara Dolnicar \\ University of Wollongong, s.dolnicar@uq.edu.au \\ J. J. Louviere \\ University of Technology, Sydney
}

See next page for additional authors

Follow this and additional works at: https://ro.uow.edu.au/commpapers

Part of the Business Commons, and the Social and Behavioral Sciences Commons

\section{Recommended Citation}

Crouch, G. I.; Oppewal, H.; Huybers, T.; Dolnicar, Sara; Louviere, J. J.; and Devinney, T.: Discretionary expenditure and tourism consumption: insights from a choice experiment 2007.

https://ro.uow.edu.au/commpapers/253

Research Online is the open access institutional repository for the University of Wollongong. For further information contact the UOW Library: research-pubs@uow.edu.au 


\title{
Discretionary expenditure and tourism consumption: insights from a choice experiment
}

\begin{abstract}
Consumers' decisions to spend money on tourism occur in the context of the other potential uses of their resources and corresponding values or utilities. While many studies have examined the demand for travel and tourism there is no known study that reveals how individuals and households make tradeoffs when allocating their spending between various potential categories of discretionary expenditure. This study assesses these tradeoffs empirically through the conduct of a choice experiment on a random sample of Australian consumers. The results provide insight into how each category of discretionary expenditure is valued and how spending in each category competes for a share of the discretionary expenditure 'pie'. We discuss the results with an emphasis on the implications for tourism.
\end{abstract}

\section{Keywords}

discretionary expenditure, tourism consumption, choice experiments

\section{Disciplines}

Business | Social and Behavioral Sciences

\section{Publication Details}

This article has been accepted for publication by Sage and will be published as: Crouch, Gl, Oppewal, H, Huybers, T, Dolnicar, S, Louviere, JJ \& Devinney, T, Discretionary expenditure and tourism consumption: insights from a choice experiment, Journal of Travel Research. Copyright Sage Publications Ltd 2007.

\section{Authors}

G. I. Crouch, H. Oppewal, T. Huybers, Sara Dolnicar, J. J. Louviere, and T. Devinney 
JOURNAL OF TRAVEL RESEARCH

Proposed Manuscript

\title{
Discretionary Expenditure and Tourism Consumption: Insights from a Choice Experiment
}

\author{
Geoffrey I. Crouch, Harmen Oppewal, Twan Huybers, Sara Dolnicar, Jordan J.
} Louviere and Timothy Devinney

\author{
Address for correspondence: \\ Professor Geoffrey I. Crouch \\ School of Business \\ La Trobe University \\ Melbourne \\ Victoria 3086 \\ Australia \\ Tel: +61394792450 \\ Fax: +61 394795971 \\ E-mail: G.Crouch@latrobe.edu.au
}

\section{Biographical Notes:}

Geoffrey I. Crouch, PhD, is Professor of Marketing in the School of Business, La Trobe University. Harmen Oppewal, PhD, is Professor of Marketing in the Department of Marketing, Monash University. Twan Huybers, PhD, is a Senior Lecturer in the School of Business, the Australian Defence Force Academy - University of New South Wales. Sara Dolnicar, PhD, is an Associate Professor in the School of Management \& Marketing at the University of Wollongong. Jordan J. Louviere, PhD, is Professor of Marketing in the School of Marketing at the University of Technology, Sydney. Timothy Devinney, PhD, is Professor and Director of the Centre for Corporate Change at the Australian Graduate School of Management.

\section{Acknowledgments:}

This research project was supported by funding from the Cooperative Research Centre for Sustainable Tourism Pty. Ltd. established by the Australian Government. We are grateful to the following members of the research Industry Reference Group: Dr. Olivia Jenkins, TTF Australia; Mr. Campbell Gome, Tourism Victoria; Mr. Michael Shiel and Mr. Stan Fleetwood, Department of Industry, Tourism and Resources; Ms. Milica Loncar, Tourism Australia; and Ms. Jane Seman, Western Australian Tourism Commission. 


\title{
Discretionary Expenditure and Tourism Consumption: Insights from a Choice Experiment
}

\begin{abstract}
Consumers' decisions to spend money on tourism occur in the context of the other potential uses of their resources and corresponding values or utilities. While many studies have examined the demand for travel and tourism there is no known study that reveals how individuals and households make tradeoffs when allocating their spending between various potential categories of discretionary expenditure. This study assesses these tradeoffs empirically through the conduct of a choice experiment on a random sample of Australian consumers. The results provide insight into how each category of discretionary expenditure is valued and how spending in each category competes for a share of the discretionary expenditure 'pie'. We discuss the results with an emphasis on the implications for tourism.
\end{abstract}

Keywords: discretionary expenditure, tourism consumption, choice experiments

\section{INTRODUCTION}

Consumers deciding to spend money on a vacation have available a wide range of other options on which they could spend money. In this regard, the decisions that consumers make reflect their judgments, or preferences, for the combination of goods and services which, ideally, constitutes some optimal allocation of expenditure or at least 'money well spent'. A fundamental issue for the tourism industry is therefore to understand the nature of the competition between classes of products - specifically, in 
this context, between tourism spending and other forms of discretionary expenditure. However, surprisingly few studies exist in this area. Tourism marketing research has addressed how alternative tourism products compete for consumer dollars but the large majority of this research addressed this competition exclusively within the tourism product category. Instead, our study attempts to get at aspects of the core issue of competition between tourism and other classes of products by addressing the question: given the many spending options available, how does tourism compete for a share of a household's discretionary use of its limited financial resources?

Answers to this question are relevant to tourism enterprises. While they may, on a dayto-day operational basis, be more focused on competition among their immediate rivals, individual tourism enterprises need also to be concerned with competition among product classes. This is particularly the case during periods when there is an increase in the cost of living (for example as a consequence rising fuel prices or interest rate increases) or when overall consumer spending on tourism declines (such as during economic downturns or following tourism shocks such as September 11). It is however also relevant for the tourism industry to know how consumers trade-off expenditure to different product classes when endeavoring to cooperate to collectively boost overall tourism demand, or interest in a particular destination. Furthermore, as a matter of public policy, the allocation of discretionary expenditure among product classes is important not only in terms of the general economic impacts but also with regard to particular industry policies. For example, in recent years the Australian government has undertaken promotion to encourage Australians to engage more in domestic tourism. Our study provides information as to whether or not this is cost effective given how consumers might treat alternatives to domestic tourism. 
To answer our fundamental research question - given the many spending options available, how does tourism compete for a share of a household's discretionary use of its limited financial resources? - this study investigates how Australian consumers would allocate extra income across different expenditure categories if they received a financial windfall. The emphasis in the study is on the patterns of substitution between tourism and other major categories of discretionary expenditure. The other major expenditure categories in this study are: reducing household debt, financial investments, home improvements/renovations, home entertainment equipment, other forms of leisure and recreation, charitable donations, and personal items (jewelry, clothing, books, etc.).

We investigated unit record data on consumer expenditure available from the Australian Bureau of Statistics to assess its usefulness in helping to answer the above research question. However, this data is not amenable to this research need, as it cannot address the issue of what consumers would do when only specific subsets of alternatives are available. We therefore constructed a purpose-specific instrument for gathering data suitable to our question. The instrument comprised a survey that included a discrete choice experiment (Louviere, Hensher and Swait 2000) in which the availability of various discretionary expenditure categories was manipulated. Members from an existing on-line panel participated in the survey. We modeled the observed hypothetical discretionary spending choices to reveal the types of substitution effects that exist across the expenditure categories, including those indicating to what extent tourism expenditures compete with expenditures in the other categories. 
In what follows we first describe the theoretical underpinnings and methodological approach of this study. The main findings from the survey are presented, followed by a discussion of the implications for tourism marketers and policy makers, particularly in circumstances when the objective is to influence consumer spending on tourism vis-àvis non-tourism alternatives.

\section{A REVIEW OF RELEVANT LITERATURE AND THEORY}

\section{The Economics of Discretionary Expenditure}

Reviewing the literature, we found only a few studies examining how individuals and families make use of funds for discretionary expenditures and none of these studies seem to have included tourism expenditure. Most work has focused on consumer purchase decisions for durables or financial services (e.g., Pickering, 1981; Soutar and Cornish-Ward, 1997). This neglect of tourism expenditure in relation to other expenditure is interesting; particularly when one considers that in developed countries a larger proportion of funds available for spending would be considered discretionary. Non-discretionary expenditure in the normal family budget includes housing expenditures (rent or mortgage), grocery and food spending, utilities and maintenance of the household, basic clothing, automobile and petrol expenses, and so on. Discretionary expenditure includes ancillary spending on housing (e.g., renovations), investment and savings, vacations and luxury items such as for example flat panel TVs. Of course the terms, discretionary and non-discretionary spending, are somewhat artificial as these are not two classes of spending. They are better understood as representing a range of spending where products lie somewhere on a discretionary/non-discretionary continuum. 
Partly for this reason, traditional economic theory has little to say about discretionary expenditure as a specific concept. Basic economic models of budget allocation and spending normally assume that all products and services are in competition with all other products and services. What matters in the majority of economic models of the consumer is that the marginal utility derived from a commodity divided by the marginal utility of a dollar of income is equalized across all options available, be they product categories or products (see, e.g., Silberberg, 1978; Ch 8). Little if anything is said about the way in which purchases are made or how the individual prioritizes specific types of expenditure (short of a marginal utility ranking) (Earl and Potts, 2000). What little additional theoretical and empirical emphasis is given to broaden expenditure modeling is found in what are known as extended linear expenditure system (ELES) models, which aim to explain general expenditure patterns but still do not go much beyond a basic utility maximization model. Variants of this model (e.g., Eastwood and Craven, 1981) introduce minimum expenditure and habitual behavior components and are generally more robust in predicting expenditure patterns. However, all they do is add a further constraint into the maximization model that consumers are assumed to be using.

Marketing scholars normally avoid studying the issue of discretionary expenditure, instead focusing on within-category competition (e.g., which brand amongst all coffee brands is being chosen) or competition between related categories (e.g., varieties of fast moving consumer goods). The marketing literature goes further than economics in giving some consideration to the psychological models behind such behavior. For example, Ratneshwar, Pechmann and Shocker (1996) look on purchasing behavior as goal-driven and argue (based upon experimental tests with undergraduates) that cross- 
product category consideration is based on whether the options available within a category can meet the salient goals (if they can, people shop only within one category) or whether the goals to be achieved by the consumer are themselves ambiguous. Similarly, Sivakumar and Raj (1997) showed that price reductions can affect switching between product categories and generally leads to switching into the "quality" end of whichever category is chosen.

Perhaps the most relevant theoretical and empirical approach from the perspective of this study is Hauser and Urban's (1986) "value priority" work. This work is neoclassical in structure, being based on utility orderings by individuals, but focuses exclusively on the ordering of expenditure between product categories. Value prioritization occurs when consumers order expenditure based on the utility achieved from the product category as long as it is above some specific level. Hauser and Urban use four means of estimating consumer budget allocation: (1) having consumers order budget items using a deck of cards, (2) having consumers provide an estimated reservation price (the price at which they would no longer purchase the item), (3) having consumers order budget items based on whether they had just won a lottery prize where they can allocate one item as the prize, and (4) having consumers choose amongst budget items as a pair of prizes to be won by a lottery where the items are based on their ordering in item (3). Hauser and Urban discovered that a value-priority approach provides a good approximation of individuals' budget plans. (Hauser and Urban compared the value priority approach with a "net value priority" approach. Net value prioritization occurs when consumers order expenditure based on the utility achieved net of the utility adjusted price of the item. Both approaches performed reasonably well). What is relevant from this research is that: (1) the ordering can be made using 
experimental methods (as used in the present study), (2) that these orderings have predictive validity, and (3) that the orderings show basic consistencies in behavior (such as delayed decisions being lower in priority when a current alternative is available; e.g., vacations today versus vacations tomorrow).

\section{Tourism Consumption and Demand}

Tourist expenditure has been the subject of numerous research studies, including those which have empirically modeled the determinants of such expenditure (see for example Ashworth and Johnson, 1990; Australian Bureau of Industry Economics, 1984; BarOn, 1981; Barry and O'Hagan, 1972; Cai, Hong and Morrison, 1995; Fuji, Khaled and Mak, 1985; Gibbons and Fish, 1985; Mak, Moncur and Yonamine, 1977; Moncur, 1978; O'Hagan and Harrison, 1984a and 1984b; Sung-Soo, Uysal and McLellan, 1991, Valk, 1983: and Yong and Gartner, 2004). In addition to expenditure studies, there are many further analyses of tourism demand employing other demand measures, most notably visitor-nights or visitor numbers.

The vast majority of such tourism demand modeling studies have taken the approach of identifying the likely exogenous variables of tourism demand, specifying a causal model that defines the longitudinal relationship between these variables and tourism demand (as the endogenous variable), and then estimating the parameters of this relationship which indicate how the variation in tourist demand over time is associated with the variation in the explanatory variables over the same time period. The most commonly employed method has been regression analysis, and the most common model specification has been log-linear, which has the advantage of producing parameters that are equivalent to estimated elasticities of demand (Crouch, 1994a). In 
these empirical studies, the most frequently employed explanatory variables of tourism demand have been tourists' disposable income, the price of tourist services in the relevant destination, measures of tourist prices in competing destinations, exchange rate changes (where international tourism has been studied), the cost of travel to the destination (usually air fares), promotional expenditure by the destination and dummy variables to account for one-off or short-term factors such as the effect of terrorist incidents, major events (such as an Olympic Games), periods of economic recession or seasonality and the like (Crouch, 1994a). It is also not uncommon to see included a long list of other, softer explanatory factors including things like cultural or trade ties, immigration links, population changes and vacation leave entitlements.

In addition to these 'causal' models of tourism demand or expenditure, another frequent approach has been to employ time-series analysis, primarily for the purpose of forecasting short-term tourism demand. As the number of demand studies in general, and analyses of tourism expenditure in particular, is very large indeed, one may refer to Crouch (1994a, 1994b), or Witt and Witt (1992) for an overview of this body of research.

Despite the accumulation of tourism demand modeling studies since the 1960s, these studies have largely neglected to consider how individuals or households make tradeoffs in their allocation of discretionary expenditure across different categories of expenditure. Crouch (1994a) found only studies of tourism expenditure that ignored other categories. Whereas numerous papers have examined the impact of income, price, airfares, exchange rates, etc. on the demand for tourism and observed tourism expenditure, the impact of the alternative use of discretionary resources has been 
overlooked. This is unfortunate as tourists in developed countries today have never before enjoyed the levels of discretionary wealth and the array of alternative discretionary spending opportunities now seen. For such consumers, spending their discretionary income on tourism is only one of the many options available to them. Hence, the tourism and marketing literature provides us with little guidance as to how consumers choose between tourism and non-tourism options available to them when they have extra income to spend. Conversely, we also do not know how, and for what categories, consumers will limit their discretionary expenditure in times of reduced economic prosperity.

Decision-making invariably requires tradeoffs as alternatives are evaluated. If these tradeoffs are ignored in the data modeling, the explanatory power of the models is reduced and the estimation error of demand parameters or elasticities increases. Parameter estimates will remain unbiased provided the omitted factors are uncorrelated with the variables included in econometric models. But often included and omitted variables are collinear, resulting in biased or misleading estimates. To ignore tradeoffs in discretionary spending decisions is therefore to ignore a significant part of the puzzle in understanding the demand for tourism, and the spending alternatives facing individuals and households.

One reason for this neglect in previous research is that consumer tradeoffs between varying types of goods are difficult to assess and model. This has changed with the development of discrete choice experiments as an efficient way to collect choice data and study tradeoffs. Recent methodological advances allow one to investigate the issues discussed here in new ways. That is, discrete choice experiments (hereafter 
"DCEs") permit one to observe consumer choices directly, where such choices represent outcomes of tradeoffs between alternatives that are systematically manipulated. In addition, the DCE approach ensures that the data one obtains avoid high levels of covariation among independent variables typically observed in nonexperimental data (Louviere, Hensher and Swait, 2000).

In summary, because discretionary expenditure tradeoffs have been largely ignored, most tourism marketing research and practice implicitly assumes either 1) that competitors within the tourism industry compete for a share of fixed expenditure on tourism, or 2) that they compete for a share of tourism expenditure, which varies as a function of economic cycles, interest rates, demographic factors, and the like. Their analyses ignore the fact that tourism expenditure is just one (varying) share of a larger discretionary expenditure 'pie'. This study explicitly avoids these assumptions and aims to answer the question of how particular tourism related expenditures compete with other tourism related expenditures relative to other, non-tourism types of expenditure.

As this is still a broad research question, the present study focuses only on the situation where all consumers have one single and fixed amount of extra income to spend. This makes framing of the choice experiment reasonably straight forward and also resolves the issue of the distinction between discretionary and non-discretionary expenditure. By focusing on a situation where consumers encounter a financial windfall, we observe allocations for budgets that are clearly discretionary for all respondents. Moreover, from these budget allocations we can directly infer the marginal effects of discretionary income increases, instead of having to rely on indirect 
assessments from total budget allocations, which is the typical situation when data is available from standard data sources.

\section{RESEARCH APPROACH}

\section{Design and Administration}

Perhaps the most useful and realistic way to obtain information about consumption expenditures is to ask people how they have allocated their discretionary money. Indeed, some prior studies have asked consumers where they spent their money (Wood, 2005). However, this approach is subject to several potential problems, such as: 1) few people keep adequate records of their discretionary spending that would be sufficient as a basis for modeling the tradeoffs made between classes of expenditure; 2) individuals are unlikely to be able to estimate or recall their discretionary spending with much accuracy; 3 ) even if they could recall their past or recent discretionary expenditures, individuals are unlikely to recall sufficient details about other discretionary spending options that they considered at the time but rejected in their final decisions; 4) levels of discretionary income differ between individuals, and for any person these levels may increase or decrease over time; and, 5) statistical irregularities and confounds (in the form of multicollinearity), which frequently occur with real market data, make the task of disentangling the determinants of choices into their component parts challenging (Louviere, Hensher and Swait, 2000).

To help minimize the potential for these problems to exist, we designed a survey to collect the desired data using a discrete choice experiment (hereafter, DCE). The advantage of a DCE approach, in light of the problems outlined above, is that DCEs allow one to control and manipulate variables of interest via carefully designed 
statistical experiments. This makes it possible to observe the choices that respondents make given the characteristics of each option offered. Orthogonal designs control the primary statistical concerns, discussed above, and make it possible to decompose the respondents' choices to reveal the tradeoffs that they make. The choice data can also be analyzed to test for differences in individual choices associated with various covariates (such as age, income, gender, family characteristics, etc.).

The survey consisted of three sections. The first section introduced the respondents to a hypothetical situation where AUD $\$ 2,000$ would become available to them as a oneoff tax-free payment. This figure of $\$ 2,000$ was somewhat arbitrary, but it was selected partly for simplicity and partly because it represented a sizeable but realistic amount for most consumers. At the time the survey was held many Australians had recently received a lump sum from a new government family-benefits scheme and tax cuts were also expected. The experiment, instructed respondents to assume the money could be allocated only to discretionary expenditure items from the following categories: financial investments (such as pension/superannuation contributions, payments into savings accounts or investment schemes), reducing household debt (such as mortgages, car loans or credit cards), home improvements or renovations (like replacing curtains or renovating kitchens), home entertainment equipment (such as TVs or video cameras), leisure activities (such as sports club memberships, going to concerts, movies or museums), domestic vacations, overseas vacations, and donations to charity (such as the Salvation Army, Heart Foundation or Greenpeace). The expenditures and expenditure categories included in the survey were derived from secondary research and empirical pre-studies employing open-ended questions that queried consumers about what they would do if they had an additional AUD $\$ 2,000$ to spend on whatever 
they wanted. Expenditures were included based on frequency counts of the statements made by respondents in these pilot interviews. This approach ensured that the choice experiment in the survey covered the main discretionary expenditure categories that would be considered by most people typically.

For each of the above discretionary expenditure categories respondents were first asked what type of expenditure item they would choose if the money had to be spent on that particular category alone. This served to acquaint the respondent with the task and spending categories and to obtain basic descriptive information. In light of the purpose of this study, the detailed questions about leisure and domestic or overseas tourism are particularly relevant. In terms of leisure spending, respondents were asked to indicate the activities (e.g., sports club or gym membership, sports equipment or gear, etc.) on which they would spend the money. For the tourism option, questions concerned which activities they would undertake (e.g., organized tour, driving tour, skiing, etc) and which destinations (e.g., The Coast, An Australian City, etc. for domestic and Europe, Africa, etc. for overseas) they would visit. An 'other' item was always available where respondents could describe the activity in their own words if they wished. Hence, this first part of the survey familiarized respondents with the various types of expenditure. It also provided the researchers with basic descriptive information about what each respondent envisaged doing if they could only spend their money on the selected expenditure category.

The second part of the survey presented respondents with eight experimentally designed choice scenarios in which varying subsets of expenditure options were available. For each set they had to indicate how they would allocate their AUD $\$ 2,000$ if 
the categories listed in the set were the only possible expenditure options available. Designing the choice scenarios in this way allows an analysis of the responses that reveals how tradeoffs are made between the various expenditure categories. The eight scenarios were derived from a $2^{7}$ fractional factorial main effects design. This design included one full choice set scenario, where all categories were available. The use of a fractional factorial design means that, across all scenarios, each expenditure type occurred equally often. Moreover, each type occurred equally often together with each other type. This balancing of expenditure type occurrences across the sets ensured that, in the model analyses, the effects for expenditure types are independent of each other. The eighth expenditure type (charity donation) was added to each scenario in order to provide a constant base alternative in the analysis, as is common practice in DCE's (see Louviere, Hensher and Swait, 2000). Although the choice of a base is arbitrary, Charity was selected as the base because we expected it to have the lowest choice frequency and would hence not dominate the other alternatives.

To ensure that the main effects for these expenditure types are independent from possible interaction effects (i.e., effects of joint occurrence of particular combinations of types in one scenario), a main effects experimental design plan and its 'fold-over' were used to create two versions of the survey. Each respondent was randomly allocated to one of these two versions. Hence, there were effectively two versions of the same survey. Version 1 and version 2 only differed in the composition of the choice sets; all other questions were identical. A "fold-over" is the mirror image of the original design but we reinserted the full choice set in version 2 for comparison purposes. Technically, the use of an orthogonal main effects design and its fold-over has two particular desirable statistical properties. First, all main effects are orthogonal to unobserved but 
potentially significant two-way interactions. Thus, the design that we employed protects the effects to be estimated from the most likely source of omitted variables bias, namely the two-way interactions (Louviere, Hensher and Swait, 2000). Second, the use of this design ensured that the cross effects in the extended logit model could be estimated, as explained further below.

The third section of the survey included some general socio-demographic questions about the respondent and his/her household including age, household composition, status in the labor force, and income. The latter is obviously important and was addressed in the survey in two ways, namely: 1) as the annual household income before tax, in bands roughly equivalent to the Australian income tax brackets; and, 2) the net weekly income of the entire household. The survey also asked how much the household expected to be spending for the whole of 2004 on each of the expenditure categories used in the first two sections of the survey.

The survey was held in the first week of November, 2004. Aiming for 1,000 completed surveys, a random sample of 2,766 respondents was drawn from an existing permission-based online panel. The panel comprises over 100,000 members from across Australia who gave their permission to be contacted for participation in market research. Participants have an account and receive small payments for their participation. They can use their accumulated earnings for gift vouchers or can receive the amount into their bank accounts. The demographic profile of Pureprofile panel members has been designed broadly to represent the Australian population on many key factors. 


\section{Modeling Approach}

To analyze how respondents made the tradeoffs involved in allocating the AUD $\$ 2,000$ amount across the various categories of discretionary spending, one needs a formal theory of how decisions are made and the process by which these factors combine to drive decisions. In this regard, the analysis is based on Random Utility Theory (RUT), pioneered by Thurstone (1927) and advanced by others since, most notably McFadden (1974). This method decomposes choice data into two components; a systematic component that can be explained as a function of relevant exogenous factors, and a random component that can not be explained (Crouch and Louviere, 2004; Louviere, Hensher and Swait 2000). RUT-based choice models allow one to make inferences about what choice attributes are preferred based on the observed choices made, or preferences expressed.

The mathematical modeling of choice can be undertaken using either data on real or actual choices observed in the market place (known as revealed choice or preferences), or on choices or preferences expressed in the form of surveys or choice experiments that offer respondents hypothetical alternatives in which the variables of interest are manipulated according to an experimental design. This latter approach results in what is known as stated choice or preference data. Revealed choice data offer the advantage of certainty with regard to actual choice behavior, but unfortunately suitable revealed choice data is rarely available for this type of analysis, or are available only for a limited number of choice contexts. For example, there is no revealed choice data for options not (yet) on the market. Also, there may be insufficient information about choice options considered but rejected and multi-collinearity may make it difficult to decompose effects to individual factors (Crouch and Louviere, 2004; 
Louviere, Hensher and Swait 2000). Because of these limitations and analytical problems we chose to collect stated choice data.

\section{RESULTS AND DISCUSSION}

\section{Profile of the Survey Respondents}

The survey produced 1,053 responses out of 2,766 invited participants (i.e. a response rate of $38 \%$ ). Of these, 547 completed survey version 1 and 506 completed survey version 2. The profile of the 1,053 respondents was compared to the profile of nonrespondents and to the profile of the Australian population.

Table 1 compares key demographic characteristics of respondents to the Australian population based on Australian Bureau of Statistics (ABS) data. This table demonstrates that, in terms of gender and geographic distribution by state, the survey respondents are a close representation of the Australian population. The age profiles are reasonably close as well. In terms of household income, respondents are skewed towards higher incomes, which probably reflects computer ownership. Household incomes under AUD $\$ 30,000$ per year are under-represented whereas household incomes over AUD $\$ 60,000$ per year are over-represented by the survey.

To check for response bias the characteristics of respondents were also compared to non-respondents on a range of socio-demographics. There was little difference between respondents and non-respondents except for home ownership and employment status. Respondents were somewhat more likely than non-respondents to own than rent $(68.3 \%$ of respondents compared to $63.3 \%$ of non-respondents). This may have a small impact on questions related to spending on home renovations and 
the like. On employment status, respondents were somewhat more likely than nonrespondents to work full-time (59.1\% compared to $53.8 \%$ ) and a little less likely to not be working (24.3\% compared to $28.5 \%)$. In summary, there is little to no evidence of any response bias. Indeed, these results indicate a high-quality response compared to survey research generally.

Table 1: Representativeness of Respondents

\begin{tabular}{|c|c|c|c|}
\hline Characteristic & Class & $\begin{array}{c}\text { Survey } \\
\text { Respondents }\end{array}$ & ABS Data ${ }^{1}$ \\
\hline \multirow[t]{2}{*}{ Gender $^{1}$} & Male & $49.4 \%$ & $49.8 \%$ \\
\hline & Female & $50.6 \%$ & $50.2 \%$ \\
\hline \multirow[t]{15}{*}{$\mathrm{Age}^{1}$} & $18-19$ & $2.4 \%$ & $3.6 \%$ \\
\hline & $20-24$ & $13.5 \%$ & $9.2 \%$ \\
\hline & $25-29$ & $11.3 \%$ & $8.9 \%$ \\
\hline & $30-34$ & $11.6 \%$ & $10.0 \%$ \\
\hline & $35-39$ & $9.3 \%$ & $9.6 \%$ \\
\hline & $40-44$ & $10.0 \%$ & $10.1 \%$ \\
\hline & $45-49$ & $13.1 \%$ & $9.4 \%$ \\
\hline & $50-54$ & $9.1 \%$ & $8.7 \%$ \\
\hline & $55-59$ & $5.9 \%$ & $7.9 \%$ \\
\hline & $60-64$ & $4.8 \%$ & $5.9 \%$ \\
\hline & $65-69$ & $6.5 \%$ & $4.9 \%$ \\
\hline & $70-74$ & $2.0 \%$ & $4.1 \%$ \\
\hline & $75-79$ & $0.7 \%$ & $3.6 \%$ \\
\hline & $80-84$ & $0 \%$ & $2.5 \%$ \\
\hline & $85+$ & $0 \%$ & $1.9 \%$ \\
\hline \multirow[t]{8}{*}{ State $^{2}$} & New South Wales & $33.5 \%$ & $35.2 \%$ \\
\hline & Victoria & $24.7 \%$ & $24.5 \%$ \\
\hline & Queensland & $19.3 \%$ & $16.9 \%$ \\
\hline & South Australia & $7.6 \%$ & $10.1 \%$ \\
\hline & Western Australia & $9.9 \%$ & $9.2 \%$ \\
\hline & Tasmania & $2.4 \%$ & $1.3 \%$ \\
\hline & Northern Territory & $1.0 \%$ & $0.7 \%$ \\
\hline & Australian Capital Territory & $1.6 \%$ & $2.1 \%$ \\
\hline Household & $<\$ 30,001$ & $16.4 \%$ & $35.0 \%$ \\
\hline \multirow[t]{7}{*}{ Income $^{3}$} & $\$ 30,001-\$ 60,000$ & $29.0 \%$ & $28.8 \%$ \\
\hline & $\$ 60,001-\$ 90,000$ & $22.3 \%$ & $18.9 \%$ \\
\hline & $\$ 90,001-\$ 120,000$ & $16.4 \%$ & $9.1 \%$ \\
\hline & $\$ 120,001-\$ 150,000$ & $6.1 \%$ & $4.6 \%$ \\
\hline & $\$ 150,001-\$ 180,000$ & $4.0 \%$ & $1.6 \%$ \\
\hline & $\$ 180,001-\$ 210,000$ & $2.6 \%$ & $1.1 \%$ \\
\hline & $>\$ 210,000$ & $3.2 \%$ & $1.0 \%$ \\
\hline
\end{tabular}

Notes: 1. ABS 2004 figures; 2. ABS data for June quarter 2004; 3. ABS data for 2002-2003. 


\section{Descriptive Outcomes of the Expenditure Allocations}

Table 2 presents two findings. The left hand column presents the proportion of allocations received by each category in the one full choice set that each respondent received as part of the experimental design. The right hand column indicates for each category the items that were most frequently selected if respondents could only spend their extra income on this category (asked in section one of the survey). The results indicate the overall pattern of competition between the expenditure categories. The largest share of allocations was taken up by the category 'reducing household debt' (44.6\%), followed by financial investment $(12.5 \%)$ and home improvement $(11.0 \%)$. In total, $68.0 \%$ would be used for asset building. Tourism attracted $20.6 \%$ of the total allocation, with $11.3 \%$ going to overseas travel and $9.3 \%$ to domestic travel. Home entertainment and leisure activities attracted small shares $(6.0 \%$ and $3.4 \%$ respectively), and charity takes up the smallest shares with $2.0 \%$.

For income allocated to domestic travel the survey asked what vacation type the money would be spent on and what destination would be selected. The largest portion was allocated to resort vacations (17\%) followed by driving tours (16\%) and visiting relatives or friends (14\%). City/ town trips attracted $12 \%$ of the allocated amount and "rest and relaxation" vacations attracted $10 \%$. The destination that was selected most if income is allocated to domestic travel was The Coast (35\%), followed by Tasmania (24\%) and The Outback (13\%).

When respondents had to spend their $\$ 2,000$ on overseas travel, the most frequently selected trip type was visiting friends and relatives (26\%), followed by trip to a town/city 
(14\%), culture trips $(12 \%)$ and resort experiences $(12 \%)$. The most popular overseas destination was Europe (42\%), followed by Asia (21\%) and North America (14\%).

Table 2: Main Areas of Interest in Allocating Discretionary Finances

\begin{tabular}{|c|c|c|}
\hline Category & $\begin{array}{l}\text { Proportion } \\
\text { of Total }\end{array}$ & Highest-Proportion Allocations within Category \\
\hline Reduce household debt & $44.6 \%$ & $\begin{array}{l}\text { - } \quad \text { credit card }(46.2 \%) \\
\text { - } \text { mortgage }(39.7 \%)\end{array}$ \\
\hline Financial investment & $12.5 \%$ & $\begin{array}{l}\text { - } \quad \text { shares }(42.5 \%) \\
\text { - } \quad \text { savings deposit }(22.9 \%)\end{array}$ \\
\hline $\begin{array}{l}\text { Home improvement (including } \\
\text { vacation homes and investment } \\
\text { properties) }\end{array}$ & $11.0 \%$ & $\begin{array}{l}\text { - renovate one or more rooms or kitchen }(37.6 \%) \\
\text { - install rainwater tank, solar cells or other measures } \\
\text { to support sustainable resources }(17.7 \%)\end{array}$ \\
\hline Home entertainment equipment & $6.0 \%$ & $\begin{array}{l}\text { - } \text { wide screen or digital TV }(51.1 \%) \\
\text { - home computer }(19.5 \%)\end{array}$ \\
\hline Leisure activities & $3.4 \%$ & $\begin{array}{l}\text { - going out }(41.2 \%) \\
\text { - tickets for cultural events (concerts, etc.) }(19.0 \%)\end{array}$ \\
\hline Domestic vacation & $9.3 \%$ & $\begin{array}{l}\text { Vacation type: } \\
\text { - } \text { resort experience }(16.9 \%) \\
\text { - } \text { driving tour }(16.1 \%) \\
\text { - } \text { visiting friends or relatives }(14.2 \%) \\
\text { - } \text { trip to town/city }(11.9 \%) \\
\text { - } \text { rest and relaxation }(10.0 \%) \\
\text { Destination region: } \\
\text { - } \text { the coast }(35.4 \%) \\
\text { - Tasmania }(24.2 \%) \\
\text { - } \quad \text { the outback }(13.1 \%) \\
\text { - } \text { an Australian city }(10.0 \%)\end{array}$ \\
\hline Overseas vacation & $11.3 \%$ & $\begin{array}{l}\text { Vacation type: } \\
\text { - } \text { visiting relatives or friends }(25.6 \%) \\
\text { - } \text { trip to a town/city }(13.5 \%) \\
\text { - } \text { organized tour }(10.4 \%) \\
\text { - } \text { resort experience }(11.8 \%) \\
\text { Destination continent: } \\
\text { - } \quad \text { Europe }(41.7 \%) \\
\text { - } \text { Asia }(21.3 \%)\end{array}$ \\
\hline Donation to charity & $2.0 \%$ & $\begin{array}{l}\text { - Salvation Army }(18.4 \%) \\
\text { - Red Cross }(6.7 \%)\end{array}$ \\
\hline Total & $100 \%$ & \\
\hline
\end{tabular}

As noted above, the survey also asked respondents to estimate how much they expected their household to spend in total, for the whole of 2004, on different expenditure categories, including the discretionary spending categories used in the choice experiment. We analyzed this data in order to compare the percentage of total 
estimated discretionary spending for each category with the percentages indicated in table 2. The comparison is shown in table 3 for the discretionary expenditure categories used in our experiment.

Table 3: Total versus Marginal Discretionary Spending

\begin{tabular}{lcc}
\hline \hline Category & $\begin{array}{c}\text { Percentage of Marginal } \\
\text { Discretionary Spending } \\
\text { (from table 2) }\end{array}$ & $\begin{array}{c}\text { Percentage of Total Discretionary } \\
\text { Spending }\end{array}$ \\
\hline Reducing household debt & 44.6 & 18.6 \\
Financial investment & 12.5 & 32.2 \\
Home improvement & 11.0 & 13.7 \\
Home entertainment equipment & 6.0 & 5.0 \\
Leisure activities & 3.4 & 8.8 \\
Domestic vacation & 9.3 & 5.4 \\
Overseas vacation & 11.3 & 6.4 \\
Donation to charity & 2.0 & 2.8 \\
Total & 100.0 & 100.0 \\
\hline \hline
\end{tabular}

The right hand column in table 3 indicates the percentage of total estimated spending over the full year that respondents believed they would probably spend on each category. By comparison, the centre column represents marginal discretionary spending in each category. They are marginal since these figures are derived from the allocation of the $\$ 2,000$ windfall and thus illustrate how this additional or marginal amount would be allocated over and above their normal discretionary spending behavior

At the margin there is a significantly higher propensity to spend in order to reduce household debt, and to undertake domestic and overseas travel. In contrast, at the margin, there is a significantly lower propensity to spend discretionary funds on financial investments, home renovations, leisure and charity. An interpretation of these results would be to regard those categories that are more significant at the margin as more 'luxurious' forms of discretionary spending such that, as households have more 
discretionary spending dollars, they will allocate more to these categories. Conversely, categories that are less significant at the margin are more like discretionary spending "necessities". In this respect it is interesting to note that, along with the desire to reduce household debt, there is, at the margin, a distinct desire to spend more money on domestic and overseas travel.

\section{Universal Logit Model of Discretionary Expenditure Choice}

The responses to the choice experiment were analyzed using discrete choice modeling in order to decompose the hypothetical choices according to the tradeoffs made by the survey respondents. In the choice experiment, the availability of discretionary expenditure categories was restricted and controlled according to the experimental design described earlier. When limited discretionary spending options are available, respondents are forced to make different tradeoffs and particular patterns of substitution can be observed that are not otherwise evident. We model these different tradeoffs and measure the level of substitution between different discretionary expenditure categories.

Many conventional stated choice modeling studies pertain to discrete choices between different products described by product attributes. However, our income allocation experiment elicited household preferences regarding the allocation among fixed expenditure groups in a stated context of additional discretionary income; hence, there was no variation in product attributes (cf. Oppewal, Louviere and Timmermans, 2000). The two key objectives of the study were to obtain a picture of the relative importance of each of the expenditure categories and to estimate the substitution patterns between the categories. To that end the data was organized to allow the estimation of the own- 
and cross-effects between each of the spending categories by way of the universal or mother logit model (McFadden, Tye and Train, 1977). The universal logit model is a model specification that deals with the independence of irrelevant alternatives (IIA) condition that is implicit in, for instance, the multinomial logit model. The IIA property refers to the condition that the relative probabilities of options $A$ and $B$ are independent of the inclusion of other options in the decision maker's choice set. In other words, if option C is introduced into the choice set, the probability of options A and B will decrease in proportion with their current probabilities. This assumption is violated if option C is similar to option A and dissimilar to option B. In that case, one would expect differential effects on the probabilities of options A and B. These different cross-effects are the substitution (or complementarity) effects that are estimated using the universal logit model (for examples see Oppewal and Timmermans, 1991).

In the present study context one would expect that domestic and overseas vacation expenditures are more substitutable than, for example, expenditure on an overseas vacation and expenditure to reduce household debt. The introduction, therefore, of domestic vacation as a choice option into a set containing overseas vacation and reducing household debt as options is expected to have a much greater impact on allocations for overseas vacations than would be predicted by the standard multinomial logit model. The latter model assumes that alternatives compete in proportion to their shares. The cross effects in the universal logit model capture deviations from this model; hence, cross effects measure where alternatives capture or lose a larger than proportional share when the composition of the choice set changes. Note these substitution patterns may vary across individual consumers. Segmentation analysis or 
inclusion of relevant background variables such as socio-demographic factors can help accommodate this variation in substitutability across consumers.

The survey included various socio-demographic and attitudinal variables. These were inserted as covariates in the model. Based on an evaluation of the predictive power of each of these variables, only age and the annual before-tax household income were included in the universal logit model estimations. The availability of the options was coded as a set of indicator dummies. Because we had a large number of age and income categories and only wished to illustrate how such variables can be included in the analysis, we took the category midpoints and then mean-centered the data (with frequency weighting). This allows a succinct description of the main age and income effects. For age and income, quadratic terms were specified in addition to the linear term to capture possible non-linear effects.

The utility of each of the options $i$ in the total choice set of $j$ options is hence specified as:

$U(i)=b_{i i}+\sum_{j, j \neq i} b_{i j}{ }^{*} d_{j}+b_{1^{*}} A g e+b_{2^{*}} A g e^{2}+b_{3} * \operatorname{lnc}+b_{4} * I n c^{2}+\varepsilon_{i}$

where, the $d_{j}$ are presence-absence dummies for each of the options $j(j \neq i)$,

(coded -1 for absent and +1 for present except for the reference category, which is coded zero), Age and Inc are the mean-centered age and income variables respectively, and the $b$ 's are the parameters to estimate; $\varepsilon_{i}$ is the error term. The utility of the reference category is arbitrarily set to zero.

The usual random utility assumption that respondents prefer the option that offers the highest utility applies. Since the response data represent stated income allocations 
instead of only discrete choices, the mother logit model was estimated in the following manner. The choice option in each choice set was used as the dependent variable. In the estimation, a weight equal to $(1+$ the allocated amount)/AUD $\$ 2,000$ was used, which is equivalent to weighting the responses by the allocation proportions, with a slight adjustment such that none of the weights equal zero.

A maximum likelihood procedure was used to estimate the model. The results are shown in the appendix. The chi-square value (12634) and McFadden's pseudo- $R^{2}$ (0.41) show that the model fit is very good (see Louviere, Hensher and Swait, 2000, p.54). For each alternative, the estimated parameters are the own- and cross-effects of the presence/absence of the options in the choice sets against the average observed choice set, with the age and income effects at the sample means. The expenditure category 'Charity' is the reference case. The presence/absence effects are more easily interpreted if the parameters are re-organized in a matrix as depicted in table 4 . The parameters on the diagonal are the own-effects while the off-diagonals are the crosseffects. The own effects are merely constants for the separate alternatives as they would appear in a conventional multinomial logit model. They represent the shares of the alternatives as shown earlier in table 2.

All significant cross-effects are negative which implies that the odds of money being allocated to a choice option (for instance, 'Domestic vacation') relative to the base option ('Charity') are lower if the cross-effect 'source' option (for instance, 'Overseas vacation') is also available in the choice set. For instance, the negative effect $(-0.17)$ of 'Overseas vacation' on 'Domestic vacation' indicates that the odds of allocating money to the domestic vacation category relative to the base option are smaller if the overseas 
vacation category is also present in the set. The more negative the parameter, the more similar are the two expenditure categories relative to the Charity base option. In other words, larger negative parameter values indicate greater levels of substitution. The matrix shows that the mother logit model allows the cross-effects to be asymmetric. That asymmetry is probably due to different segments having different preferences. Consider the cross-effect of household debt reduction on home renovations. The first row in table 4 indicates that when the choice set contains the option of reducing household debt, allocating discretionary resources to home renovations is significantly negatively impacted (i.e., -0.16). However, the converse is not true; that is, when the option of home renovation is available in the choice set (third row in the table), there is no significant effect on household debt reduction (i.e., -0.01).

Table 4: Matrix of Estimated Own and Cross Effects ${ }^{1}$

\begin{tabular}{|c|c|c|c|c|c|c|c|}
\hline \multirow[b]{2}{*}{$\begin{array}{l}\text { When Option Below is } \\
\text { Present }\end{array}$} & \multicolumn{7}{|c|}{ Impact of Allocating Expenditure to these Options is: ${ }^{2}$} \\
\hline & $\begin{array}{l}\text { Reduce } \\
\text { HH Debt }\end{array}$ & $\begin{array}{l}\text { Financial } \\
\text { Investment }\end{array}$ & $\begin{array}{c}\text { Home } \\
\text { Renovation }\end{array}$ & $\begin{array}{c}\text { Home } \\
\text { Entertainment }\end{array}$ & $\begin{array}{l}\text { Leisure } \\
\text { Activity }\end{array}$ & $\begin{array}{l}\text { Domestic } \\
\text { Vacation }\end{array}$ & $\begin{array}{l}\text { Overseas } \\
\text { Vacation }\end{array}$ \\
\hline Reduce HH Debt & $4.04^{* *}$ & $-0.17^{*}$ & $-0.16^{*}$ & -0.08 & -0.04 & -0.14 & -0.09 \\
\hline Financial Investment & 0.02 & $2.89 * *$ & -0.09 & $-0.18^{* *}$ & -0.11 & 0.01 & -0.07 \\
\hline Home Renovation & -0.01 & -0.08 & $2.96^{* *}$ & -0.12 & -0.07 & $-0.15^{*}$ & -0.03 \\
\hline Home Entertainment & $-0.14^{*}$ & -0.09 & $-0.17^{*}$ & $2.14^{* *}$ & -0.14 & -0.09 & -0.03 \\
\hline Leisure Activity & -0.09 & -0.12 & -0.12 & -0.08 & $1.68^{* *}$ & -0.05 & -0.13 \\
\hline Domestic Vacation & -0.09 & -0.10 & -0.14 & -0.06 & $-0.20^{* *}$ & $2.73^{* *}$ & $-0.23^{* *}$ \\
\hline Overseas Vacation & 0.10 & 0.07 & 0.06 & -0.09 & -0.15 & $-0.17^{*}$ & $2.85^{\star *}$ \\
\hline
\end{tabular}

The pattern of results displayed in table 4 shows that the significant substitution effects are generally observed within two groups of expenditure categories. The first group consists of Reducing Household Debt, Financial Investment, Home Renovations and Home Entertainment expenditure, while the second group comprises Domestic Vacation, Overseas Vacation and Leisure. While there are significant cross-effects 
within these two groups, all but one of the cross-effects between the two groups' categories are insignificant. In other words, the presence of an expenditure category from one group in the choice set does not significantly affect the allocation of discretionary income to a category from the other group (relative to the base category "Charity'). This implies that the presence effect of, for instance, reducing household debt on relative tourism and leisure allocations is, on average, insignificant. It should be noted however that this result applies across the sample; the effect may be significant for certain segments.

The estimated parameters for age and income (see appendix) show the significant relationships of these covariates with the propensity to spend among the various categories. According to the model, as income and age increase, expenditure on most categories increases (but at a decreasing rate) whereas spend on home entertainment and charity decreases. The model for example predicts that the highest expenditure on domestic vacations will be observed for consumers aged 54 with a pre-tax household income of AUD $\$ 143,000$.

The utility functions (equation 1) can be used, in the conventional way, to calculate the aggregate probabilities for each of the options according to the multinomial logit model (Ben-Akiva and Lerman 1985):

$$
\operatorname{Pr}(i)=\frac{e^{U_{i}}}{\sum_{j} e^{U_{j}}}
$$

Equation 2 represents the probability of choosing option $i$ as a function of the utility of option $\mathrm{i}\left(\mathrm{U}_{\mathrm{i}}\right)$ and the utility of all other options $\left(\mathrm{U}_{\mathrm{j}}\right)$. The resulting aggregate probabilities 
can be interpreted as the predicted shares of how respondents would spend the $\$ 2,000$, for each of the options at the sample means for age and income.

One of the main benefits of our model is that it can be used to predict the aggregate shares in cases where not all options are considered. Table 5 shows the predicted and implied shares of how respondents would allocate the $\$ 2,000$, for the scenario in which households are considering the choice between leisure activities, a domestic vacation and an overseas vacation. The model predictions are based on the model with only those parameters that are significant at alpha is 10 percent (see table 4). The implied shares based on table 2 are very different compared to the predicted shares from the experimental choice model. The simple inference from the full choice set would be that overseas vacations take the largest share of the allocations $(47 \%)$, with domestic vacations taking only $39 \%$. The model however predicts a higher spend for domestic vacations, with overseas vacations taking $44 \%$ and domestic $42 \%$ share. This difference results from the cross-effects in the universal logit model allowing for nonDeleted: 47 Deleted: only 39 proportional substitution between the categories. Apparently, when the options for spending discretionary income are restricted to these three categories only, more consumers opt to switch to domestic vacations than to overseas vacations.

Table 5: Predicted and Implied Shares for Choice Between Domestic Vacation, Overseas Vacation \& Leisure Categories

\begin{tabular}{|c|c|c|c|}
\hline & $\begin{array}{c}\text { Predicted shares from } \\
\text { experimental choice } \\
\text { model }\end{array}$ & $\begin{array}{l}\text { Implied shares derived } \\
\text { from full choice set } \\
\text { condition (table 2) }\end{array}$ & \\
\hline \multirow{4}{*}{$\begin{array}{l}\text { Leisure } \\
\text { Domestic vacation } \\
\text { Overseas vacation } \\
\text { Total }\end{array}$} & \multirow{4}{*}{$\begin{array}{l}14.2 \% \\
41,8 \% \\
44,0 \% \\
100.0 \%\end{array}$} & \multirow{4}{*}{$\begin{array}{c}14.1 \% \\
\ldots \\
\ldots\end{array}$} & Deleted: 4 \\
\hline & & & Deleted: 3 \\
\hline & & & Deleted: 46 \\
\hline & & & \multirow{2}{*}{\begin{tabular}{|l|} 
Deleted: 5 \\
Deleted: 39
\end{tabular}} \\
\hline & & & \\
\hline & & & Deleted: 2 \\
\hline
\end{tabular}




\section{CONCLUSIONS AND DISCUSSION}

This study aimed to identify how tourism competes against six other main categories of discretionary expenditure. It found that tourism attracts 21 percent of discretionary income, when such expenditure is measured as the average amount that respondents would spend on domestic and overseas vacations if they could spend a AUD $\$ 2,000$ windfall. The results indicate that a larger amount would be spent on overseas travel than on domestic travel. However, when forced to choose between only leisure activities, domestic vacations and overseas vacations a majority of the expenditure would be directed towards domestic vacations.

Across all choice conditions the largest portion of discretionary spending $(45 \%)$ went to reducing household debt, in particular to credit card and mortgage repayments. The next most important items, attracting approximately equal amounts on average, were financial investments, home improvements, overseas vacations, and domestic vacations, each accounting for between about 9 to 13 percent of discretionary expenditure. Home entertainment accounted for 6 percent; leisure activities took 3 percent and charity received 2 percent.

In Australia, various tourism marketing campaigns in the past have endeavored to encourage Australians to vacation within Australia. Our findings support the rationale for these endeavors, but only to some extent. Our results indicate that domestic tourism expenditure competes relatively strongly, but not exclusively, with international tourism expenditure. Other major competing categories in our study are leisure activities and home renovations and, although to a lesser extent, also the remaining categories of 
savings, investments and home entertainment. This highlights that the domestic tourism industry competes globally for a share of discretionary household expenditure while at the same time also competing with a range of other expenditure categories. Marketing campaigns to support domestic tourism could therefore target a wide range consumer types and do not just need to focus on convincing consumers to travel within their own country rather than vacationing abroad.

This study is only one attempt to investigate this issue and clearly more research is required into how tourism competes with other expenditure categories. Our analysis of tradeoffs between categories of stated discretionary spending has been based on a choice experiment in which respondents were asked to allocate a windfall income of AUD $\$ 2,000$ across various constrained categories. The results therefore provide important information as to how Australians are likely to allocate this sum of money under these conditions, and how they broadly feel about, and value, various discretionary spending options in general. It is important to note, however, that the results could have been somewhat different had the amount of windfall income been significantly larger or smaller. For example, much larger amounts are likely to result in a lower proportional allocation to household debt reduction (since debts are finite) and a higher proportional allocation to financial investment. Also, spending behavior in relation to windfall income may not necessarily be the same as spending behavior when real salaries and wages increase (decrease), tax burdens change, inflation or interest rate changes affect real incomes, etc. as these changes apply over some future period rather than as a one-off event such as a windfall. Nevertheless, the results from this study may broadly indicate attitudes and behaviors in relation to discretionary spending in general. 
The results of our survey and choice experiment indicate how discretionary expenditure might be reallocated if individuals were to decide to allocate a different proportion of discretionary expenditure to servicing debt, for example due to an increase in mortgage interest rates. Across the sample, any significant change in the desire or need to reduce household debt would be expected to have a significant and disproportionate effect on financial investments and home renovations. Consequently, for the other expenditure categories, the reallocation of discretionary expenditure from servicing debt to those other categories is somewhat less than proportional to their shares.

Events that impact discretionary spending (such as declining real wages, changes in general interest rates, or changes in the cost of living) will normally influence each and every category of discretionary spending. In the absence of cross-effects indicative of disproportionate substitution, increases or decreases in the discretionary expenditure budget impact categories proportionally. The presence of significant substitution or cross-effects indicates where this proportional pattern is distorted. The results of this research identified where a number of significant cross-effects exist. Overall, however, there was not evidence of large, wide-scale cross-effects. This does not mean that changes in discretionary spending on one category do not affect the other categories. Rather, it indicates that most substitution is approximately proportional, with some disproportional substitution in a few cases. This implies that, at the aggregate level, tourism will be substantially affected by changes in discretionary income, regardless of the conditions, or source, of the income increase or decrease. 
In terms of the implications for tourism marketing and public policy, the demand for domestic and overseas tourism is obviously dependent on the size of the discretionary expenditure budget. Any event that impacts this budget (for example the recent escalation in oil prices) will at least impact the quantum of spending in each category but may well also impact its distribution depending on the nature of the event. In the context of this research, impacts on the discretionary servicing of household debt ought to be a major interest to tourism marketers. It is critical that tourism enterprises are aware of these impacts if they are to understand and therefore respond appropriately, when important fundamental changes occur. Additionally, competition from international (overseas) tourism is clearly demonstrated by these results. Events that change the availability of international travel and tourism (such as the threat of terrorism, bird flu, oil prices, and economic problems) are particularly relevant. Should these international issues grow worse, domestic tourism operators in Australia could expect (all other things remaining constant) an increase in spending on domestic travel. However, in such a situation, the results of this research suggest that only a relatively small proportion of all spending on overseas vacations would be diverted to domestic vacations. Consumers will reconsider their options and domestic tourism will have to compete with other discretionary expenditure options for attracting the budgets that remain unspent on overseas vacations. If these international concerns improve, however, the reverse could be expected to occur.

The approach developed and tested here could be extended to understand better these broader issues of cross-category competition. Further work using hypothetical budget allocations as demonstrated here could reveal how sensitive households are to changes in debt or interest rates. The current study did not vary debt or interest rates 
as factors in the design, hence the respondents' discretionary expenditure allocations are only observed for their current levels of debt and interest. However, by adding such information to the scenarios and then observing how consumer allocations change, it would be possible to answer questions such as these. Although complicating the experimental design, adding such factors in principle is straightforward and would constitute a novel approach to the study of tourism expenditure. A similar approach has shown promising results in the context of entrepreneurial decision making (see Oppewal, Louviere and Timmermans, 2000).

The present work could also be replicated and extended to study the effects of variations in extra income, the effects of the timing of the income becoming available, the time horizon within which the income must be spent, or the effects of possible income reductions. Further work also could incorporate scenarios where not only more or less income were available but also where the socio-economic or environmental context is varied; allowing one to study the impact of broad societal or market changes such as changing competition due to the arrival of discount airlines, changed awareness of security issues, or changes in the economic climate such as interest rates or exchange rates.

Finally, the findings in this study are reported across all respondents. In future research it would be interesting to investigate in detail the heterogeneity among households with regard to discretionary expenditure. As discussed, the pattern of cross-effects, with two groups of spending categories emerging, may be attributed to the existence of different household segments with different preferences for spending discretionary funds. A study of heterogeneity could lead to the identification of household segments that 
spend more of their discretionary expenditure on tourism and would thus represent an attractive target market for the tourism industry. 
APPENDIX - Estimated Parameters from the Universal Logit Model

\begin{tabular}{|c|c|c|c|c|c|}
\hline Alternative & & b & s.e & Wald & Sign. \\
\hline \multirow{11}{*}{$\begin{array}{l}\text { Reducing household } \\
\text { debt }\end{array}$} & Red. HH debt & 4.04 & 0.12 & 1175.49 & 0.00 \\
\hline & Financial investment & 0.02 & 0.09 & 0.05 & 0.82 \\
\hline & Home renovation & -0.01 & 0.09 & 0.02 & 0.89 \\
\hline & Home entertainment & -0.14 & 0.09 & 2.74 & 0.10 \\
\hline & Leisure activity & -0.09 & 0.09 & 1.13 & 0.29 \\
\hline & Domestic vacation & -0.09 & 0.09 & 1.12 & 0.29 \\
\hline & Overseas vacation & 0.10 & 0.09 & 1.26 & 0.26 \\
\hline & Age (mean-centred) & 0.01 & 0.01 & 7.42 & 0.01 \\
\hline & Age (quadratic) & 0.00 & 0.00 & 79.62 & 0.00 \\
\hline & Income (mean-centred) & 0.01 & 0.00 & 9.27 & 0.00 \\
\hline & Income (quadratic) & 0.00 & 0.00 & 16.68 & 0.00 \\
\hline \multirow[t]{11}{*}{ Financial investment } & Red. $\mathrm{HH}$ debt & -0.17 & 0.09 & 3.51 & 0.06 \\
\hline & Financial investment & 2.89 & 0.12 & 611.34 & 0.00 \\
\hline & Home renovation & -0.08 & 0.09 & 0.90 & 0.34 \\
\hline & Home entertainment & -0.09 & 0.09 & 1.11 & 0.29 \\
\hline & Leisure activity & -0.12 & 0.09 & 1.72 & 0.19 \\
\hline & Domestic vacation & -0.10 & 0.09 & 1.17 & 0.28 \\
\hline & Overseas vacation & 0.07 & 0.09 & 0.59 & 0.44 \\
\hline & Age (mean-centred) & 0.01 & 0.01 & 6.90 & 0.01 \\
\hline & Age (quadratic) & 0.00 & 0.00 & 20.84 & 0.00 \\
\hline & Income (mean-centred) & 0.01 & 0.00 & 9.29 & 0.00 \\
\hline & Income (quadratic) & 0.00 & 0.00 & 10.29 & 0.00 \\
\hline \multirow[t]{11}{*}{ Home renovation } & Red. $\mathrm{HH}$ debt & -0.16 & 0.09 & 2.92 & 0.09 \\
\hline & Financial investment & -0.09 & 0.09 & 0.98 & 0.32 \\
\hline & Home renovation & 2.96 & 0.12 & 640.09 & 0.00 \\
\hline & Home entertainment & -0.17 & 0.09 & 3.51 & 0.06 \\
\hline & Leisure activity & -0.12 & 0.09 & 1.97 & 0.16 \\
\hline & Domestic vacation & -0.14 & 0.09 & 2.48 & 0.12 \\
\hline & Overseas vacation & 0.06 & 0.09 & 0.49 & 0.48 \\
\hline & Age (mean-centred) & 0.04 & 0.01 & 46.35 & 0.00 \\
\hline & Age (quadratic) & 0.00 & 0.00 & 63.76 & 0.00 \\
\hline & Income (mean-centred) & 0.00 & 0.00 & 3.01 & 0.08 \\
\hline & Income (quadratic) & 0.00 & 0.00 & 5.86 & 0.02 \\
\hline \multirow[t]{11}{*}{ Home entertainment } & Red. HH debt & -0.08 & 0.09 & 0.75 & 0.39 \\
\hline & Financial investment & -0.18 & 0.09 & 4.23 & 0.04 \\
\hline & Home renovation & -0.12 & 0.09 & 1.68 & 0.19 \\
\hline & Home entertainment & 2.14 & 0.12 & 323.93 & 0.00 \\
\hline & Leisure activity & -0.08 & 0.09 & 0.71 & 0.40 \\
\hline & Domestic vacation & -0.06 & 0.09 & 0.47 & 0.49 \\
\hline & Overseas vacation & -0.09 & 0.09 & 1.01 & 0.32 \\
\hline & Age (mean-centred) & 0.01 & 0.01 & 2.12 & 0.14 \\
\hline & Age (quadratic) & 0.00 & 0.00 & 16.15 & 0.00 \\
\hline & Income (mean-centred) & 0.00 & 0.00 & 0.94 & 0.33 \\
\hline & Income (quadratic) & 0.00 & 0.00 & 1.73 & 0.19 \\
\hline \multirow[t]{5}{*}{ Leisure activities } & Red. HH debt & -0.04 & 0.10 & 0.14 & 0.71 \\
\hline & Financial investment & -0.11 & 0.10 & 1.23 & 0.27 \\
\hline & Home renovation & -0.07 & 0.09 & 0.57 & 0.45 \\
\hline & Home entertainment & -0.14 & 0.10 & 2.13 & 0.14 \\
\hline & Leisure activity & 1.68 & 0.12 & 188.58 & 0.00 \\
\hline
\end{tabular}




\begin{tabular}{llrrrr} 
& Domestic vacation & -0.20 & 0.10 & 4.06 & 0.04 \\
& Overseas vacation & -0.15 & 0.10 & 2.36 & 0.12 \\
& Age (mean-centred) & 0.00 & 0.01 & 0.26 & 0.61 \\
& Age (quadratic) & 0.00 & 0.00 & 11.25 & 0.00 \\
& Income (mean-centred) & 0.00 & 0.00 & 2.57 & 0.11 \\
& Income (quadratic) & 0.00 & 0.00 & 3.73 & 0.05 \\
\hline Domestic vacation & Red. HH debt & -0.14 & 0.09 & 2.35 & 0.13 \\
& Financial investment & 0.01 & 0.09 & 0.01 & 0.91 \\
& Home renovation & -0.15 & 0.09 & 2.77 & 0.10 \\
& Home entertainment & -0.09 & 0.09 & 0.92 & 0.34 \\
& Leisure activity & -0.05 & 0.09 & 0.32 & 0.57 \\
& Domestic vacation & 2.73 & 0.12 & 552.80 & 0.00 \\
& Overseas vacation & -0.17 & 0.09 & 3.68 & 0.06 \\
& Age (mean-centred) & 0.03 & 0.01 & 22.11 & 0.00 \\
& Age (quadratic) & 0.00 & 0.00 & 27.30 & 0.00 \\
& Income (mean-centred) & 0.00 & 0.00 & 4.58 & 0.03 \\
& Income (quadratic) & 0.00 & 0.00 & 8.03 & 0.00 \\
\hline Overseas vacation & Red. HH debt & -0.09 & 0.09 & 0.97 & 0.32 \\
& Financial investment & -0.07 & 0.09 & 0.50 & 0.48 \\
& Home renovation & -0.03 & 0.09 & 0.13 & 0.72 \\
& Home entertainment & -0.03 & 0.09 & 0.10 & 0.75 \\
Leisure activity & -0.13 & 0.09 & 2.14 & 0.14 \\
Model fit: & Leudo R-Square & -0.23 & 0.09 & 6.76 & 0.01 \\
& Domestic vacation & 2.85 & 0.12 & 577.00 & 0.00 \\
& Overseas vacation & 0.01 & 0.01 & 6.46 & 0.01 \\
& Age (mean-centred) & 0.00 & 0.00 & 12.87 & 0.00 \\
& Age (quadratic) & 0.00 & 12.61 & 0.00 \\
& Income (mean-centred) & 0.01 & 0.00 & 15.39 & 0.00 \\
& Income (quadratic) & 0.00 & 0.00 & & \\
& & & & & \\
\hline
\end{tabular}




\section{REFERENCES}

Ashworth, J. \& P. Johnson (1990). "Holiday Tourism Expenditure: Some Preliminary Econometric Results". The Tourist Review, 3: 12-19.

Australian Bureau of Industry Economics (1984). Tourist Expenditure in Australia (Research Report No. 16).

BarOn, R. R. V. (1981). The Volume and Expenditures of International Tourism Comparable Estimates To and From the Principle Countries, Jerusalem: Israel Ministry of Tourism and School of Tourism.

Barry, K. \& O'Hagan, J. (1972). An Econometric Study of British Tourist Expenditure in Ireland. Economic and Social Review, 3: 143-161.

Ben-Akiva, Moshe and Steven R. Lerman (1985). Discrete Choice Analysis, The MIT Press: Cambridge, Massachusetts.

Cai, Liping A., Gong-Soong Hong and Alastair M. Morrison (1995). "Household Expenditure Patterns for Tourism Products and Services", Journal of Travel and Tourism Marketing, 4 (4): 15-40.

Crouch, Geoffrey I. (1994a). "The Study of International Tourism Demand: A Survey of Practice", Journal of Travel Research, 32 (4): 41-55. 
Crouch Geoffrey I. (1994b). "The Study of International Tourism Demand: A Review of Findings", Journal of Travel Research, 33 (1): 12-23.

Crouch, Geoffrey I. and Jordan J. Louviere (2001). "A Review of Choice Modelling Research in Tourism, Hospitality and Leisure", in Consumer Psychology of Tourism, Hospitality and Leisure - Volume 2, J. A. Mazanec, G. I. Crouch, J. R. B. Ritchie, and A. G. Woodside (eds.), CABI Publishing, Wallingford, UK, 67-86.

Crouch, Geoffrey I. and Jordan J. Louviere (2004). "The Determinants of Convention Site Selection: A Logistic Choice Model from Experimental Data", Journal of Travel Research, 43 (2): 118-130.

Earl, P. E., and J. Potts (2000). "Latent Demand and the Browsing Shopper," Managerial and Decision Economics, 21 (3/4): 111-122.

Eastwood, D. and J. Craven (1981). "Food Demand and Savings in a Complete, Extended, Linear Expenditure System," American Journal of Agricultural Economics, 63 (3): 544-549.

Fujii, E. T., M. Khaled, and J. Mak (1985). "An Almost Ideal Demand System for Visitor Expenditures", Journal of Transport Economics and Policy, 19: 161-171.

Gibbons, J. D. and M. Fish (1985). "Devaluation and U.S. Tourism Expenditures in Mexico", Annals of Tourism Research, 12: 547-561. 
Hauser, J. and G. Urban (1986). "The Value Priority Hypotheses for Consumer Budget Plans," Journal of Consumer Research, 12 (March): 446-462.

Louviere, Jordan J., David A. Hensher and Joffre D. Swait (2000). Stated Choice Methods: Analysis and Application, Cambridge University Press: Cambridge, UK.

Mak, James, James Moncur, and D. Yonamine (1977). "Determinants of Visitor Expenditures and Visitor Lengths of Stay: A Cross-Section Analysis of U.S. Visitors to Hawaii". Journal of Travel Research, 15 (3): 5-8.

McFadden, Daniel (1974). "Conditional Logit Analysis of Qualitative Choice Behavior", in Frontiers in Econometrics, P. Zarambka (ed.), Academic Press: New York.

McFadden, D., W. Tye and K. Train (1977). "An Application of Diagnostic Tests for the Irrelevant Alternatives Property of the Multinomial Logit Model", Transportation Research Record, 637: 39-46.

Moncur, J. E. T. (1978). Thailand's Tourism: An Analysis of Visitor Length of Stay and Expenditures, Faculty of Economics, Thammasat University. Discussion Paper Series.

O'Hagan, J. W. and M. J. Harrison (1984a). "Market Shares of U.S. Tourist Expenditures in Europe: An Econometric Analysis", Applied Economics, 16: 919931. 
O'Hagan, J. W. and M. J. Harrison (1984b). "U.K. and U.S. Visitor Expenditure in Ireland: Some Econometric Findings", The Economic and Social Review, 15: 195-207.

Oppewal, Harmen, Jordan J. Louviere and Harry J. P. Timmermans (2000). "Modifying Conjoint Methods to Model Managers' Reactions To Business Environmental Trends: An Application to Modeling Retailer Reactions To Sales Trends", Journal of Business Research, 50 (3): 245-257.

Oppewal, Harmen and Harry J. P. Timmermans (1991). "Context Effects and Decompositional Choice Modelling", Papers in Regional Science, 70 (2): $113-131$.

Pickering, J.F.(1981). "A Behavioural Model of the Demand for Consumer Durables", Journal of Economic Psychology, 1: 59-77.

Ratneshwar, S., C. Pechmann and A. Shocker (1996). "Goal-Derived Categories and the Antecedents of Across Category Consideration," Journal of Consumer Research, 23 (December): 240-250.

Sivakumar, K. and S.P. Raj (1997). "Quality Tier Competition: How Price Change Influences Brand Choice and Category Choice," Journal of Marketing, 61 (July): $71-84$. 
Silberberg, E. (1978). The Structure of Economics, McGraw-Hill: New York, New York.

Soutar, G. N. and S.P. Cornish-Ward (1997). "Ownership Patterns for Durable Goods and Financial Assets: a Rasch Analysis," Applied Economics, 29: 903-911.

Sung-Soo, P., M. Uysal and R. W. McLellan (1991). "A Linear Expenditure Model for Tourism Demand", Annals of Tourism Research, 18: 443-454.

Thurstone, L. L. (1927). "A Law of Comparative Judgment", Psychological Review, 34: 273-286.

Valk, P. v. d. (1983). "The Influence of Foreign Price Developments on the Choice of Holiday Destination and Holiday Expenditure by Netherlands People", SociaalCultureel Kwartaalbericht, 5, 102.

Wood, Michael (2005). "Discretionary Unplanned Buying in Consumer Society", Journal of Consumer Behaviour, 4 (4): 268-281.

Witt, Stephen F. and Christine A. Witt (1992). Modelling and Forecasting Demand in Tourism, Academic Press: London.

Yong, K. S. and W. C. Gartner (2004). "Preferences and Trip Expenditures - A Conjoint Analysis of Visitors to Seoul, Korea", Tourism Management, 25: 127-137.

JTR discret paper (v9).doc 